\title{
PENGEMBANGAN INSTRUMEN PENGKAJIAN ASUHAN KEPERAWATAN PADA PASIEN GERONTIK DI RSUD BANYUASIN
}

\author{
Ani Syafriati \\ Program Studi S1 Keperawatan STIKES Mitra Adiguna Palembang. \\ Komplek Kenten Permai Blok J No 9-12 Bukit Sangkal Palembang 30114 \\ Email : syafriatiani92@gmail.com
}

\begin{abstract}
Abstrak
Penilaian geriatric menggunakan alat khusus untuk membantu menentukan pasien status di beberapa sistem yang berbeda, termasuk penilaian medis, kognitif, afektif, sosial, ekonomi, lingkungan, spiritual, dan fungsional status. Untuk meninjau alat khusus yang praktisi dapat digunakan dalam skrining mereka untuk sindrom geriatric ketika mengevaluasi pasien. Desain kegiatan ini menggunakan pendekatan mix-method (kualitatif-kuantitatif). Dimana tahap pertama akan melakukan pengembangan instrument pengkajian keperawatan geriatric dengan melakukan wawancara mendalam dengan perawat dan dokter spesialis penyakit dalam. Selanjutnya, setelah dilakukan uji pakar untuk instrument tersebut, maka dilanjutkan dengan uji coba (validitas dan reliabilitas) instrument pengkajian keperawatan geriatric pada 15 lansia di RSUD Banyuasin. Didapatkan instrumen pengkajian gerontic dan dilakukan uji instrumen. Hasil analisis Aiken's V pada dua pakar yaitu 11 item pengkajian asuhan keperawatan geriatri dinyatakan valid (pada lampiran 6), dibuktikan hasil analisis berkisar antara 0,667-1. Hasil uji korelasi biseral, dikatakan valid apabila nilai thitung > t tabel. Untuk nilai t hitung berdasarkan tabel $t$ dengan $n=30(30-2=28)$, signifikansi 5\% = 2,048. Hasil uji KR20 didapatkan Berdasarkan hasil uji reliabilitas pengkajian asuhan keperawatan geriatri ini didapatkan hasil yaitu varian total 9,09 dengan reliabilitas sebesar 0,90. Berdasarkan hasil pengembangan instrument pengkajian asuhan keperawatan khusus gerontic di RSUD Banyuasin didapatkan instrument dan penerapan instrument yang dilakukan selama 2 minggu.
\end{abstract}

Kata kunci : Instrumen, Gerontik, Pengembangan.

\begin{abstract}
Geriatric assessment uses specialized tools to help determine patient status in several different systems, including assessment of medical, cognitive, affective, social, economic, environmental, spiritual, and functional status. To review the specific tools that practitioners can use in their screening for geriatric syndromes when evaluating patients.: The design of this activity uses a mix-method (qualitative-quantitative) approach. Where the first stage will be to develop a geriatric nursing assessment instrument by conducting in-depth interviews with nurses and internal medicine specialists. Furthermore, after expert testing for the instrument, it was continued with a trial (validity and reliability) of the geriatric nursing assessment instrument on 15 elderly people at the Banyuasin Hospital. The gerontic assessment instrument was obtained and the instrument test was carried out. The results of Aiken's $V$ analysis on two experts, namely 11 items of assessment of geriatric nursing care were declared valid (in appendix 6), as evidenced by the results of the analysis ranging from 0.667 1. The results of the biseral correlation test are said to be valid if the value of $t$ count $>t$ table. For the calculated $t$ value based on the t table with $n=30(30-2=28)$, the significance of $5 \%=2.048$. The results of the KR2O test were obtained. Based on the results of the reliability test of the geriatric nursing care assessment, it was obtained that the total variance was 9.09 with a reliability of 0.90. Conclusion: Based on the results of the development of the gerontic special nursing care assessment instrument at the Banyuasin Hospital, it was found that the instrument and the application of the instrument were carried out for 2 weeks.
\end{abstract}

Keywords: Instruments, Gerontics, Development. 


\section{PENDAHULUAN}

Proses menua di dalam perjalan hidup manusia merupakan suatu hal yang wajar yang akan dialami semua orang yang dikaruniai panjang umur. Hanya cepat lambatnya proses itu bergantung pada individu masing-masing yang bersangkutan. Secara individu, pengaruh proses menua dapat ditimbukan dari berbagai masalah baik secara fisik, biologi, menta maupun sosial ekonomi. Semakin lanjut usia seseorang, ia akan mengalami kemunduran terutama di bidang kemampuan fisik, yang dapat mengakibatkan penurunan pada peran peran sosialnya. Hal ini juga mengakibatkan gangguan pada kebutuhan hidupnya sehingga dapat meningkatkan ketergantungan yang memerukan bantuan orang lain (Brown et.al, 2019).

Lanjut usia tidak hanya ditandai dengan kemunduran fisik, tetapi dapat pula berpengaruh pada kondisi mental, semakin lanjut usinya maka semakin berkurang aktivitas sosialnya dan dapat mengakibatkan berkurangnya integrasi dengan lingkungannya. Pada usia mereka yang lanjut sebagian dari mereka masih memilikii kemampuan untuk bekerja, dan permasalahannya adalah bagaimana mereka menggunakan tenaga dan kemampuan mereka dalam situasi keterbatasan kesempatan bekerja. Penuaan tidak terjadi secara tiba-tiba, tetapi perkembangan dari masa ke masa dari bayi hingga menjadi tua (Bullock et.al, 2019).

Lanjut usia dipandang sebagai masa degenerasi biologis yang disertai dengan berbagai penderitaan akibat berbagai macam penyakit yang menyertai proses menua (masa rentan penyakit dan mengalami kemunduran). Proses keperawatan dalam lansia ini menjalankan peran dan tanggung jawab terhadap tatanan pelayanan kesehatan dengan manggunakan ilmu pengetahuan, keahlian, keterampilan, teknologi, dan seni dalam merawat untuk meningkatkan fungsi optimal lanjut usia secara komprehensif (Eichhorn et.al, 2019).

Sebagai pemberi layanan, perawat memberikan pelayanan secara langsung kepada lansia dalam berbagai situasi. Perawat harus mampu memahami proses penyakit yang umum terjadi pada lansia termasuk pengetahuan tentang latar belakang penyakit, resiko, faktor resiko, tanda dan gejala, terapi medikasi, asuhan keperawatan, dan rehabilitasi yang dapat diberikan pada lansia tersebut. Sedangkan terkait perawat sebagai pengajar, perawat gerontik fokus untuk memberikan pelayanan dan pengajaran pada lansia dan faktor-faktor resiko yang dimodifikasi melalui promosi kesehatan dan pelayanan kesehatan. Perawat memiliki peranan untuk menjaga populasi lansia tentang cara mengurangi resiko gangguan penyakit yang merupakan penyebab utama kematian lansia. Peran perawat gerontik sebagai manager dengan tugas menyeimbangkan antara kekhawatiran pasien, keluarga, perawat, dan tenaga kesehatan lainnya (Kameyama et.al, 2018).

Selain penyakit medis, psikologis, masalah sosial, kognitif, dan fungsional mempengaruhi kesehatan orang tua. Karena itu, tradisional penilaian medis (riwayat penyakit saat ini, riwayat medis masa lalu, tinjauan sistem, fisik pemeriksaan, dan evaluasi laboratorium) sendiri seringkali tidak cukup untuk mengevaluasi populasi yang lebih tua dengan berbagai komorbiditas. Dari ini diakui perlu, penilaian geriatri telah dikembangkan, yang menekankan pendekatan yang berbeda dari evaluasi medis standar. Penilaian geriatric 
menggunakan alat khusus untuk membantu menentukan pasien status di beberapa sistem yang berbeda, termasuk penilaian medis, kognitif, afektif, sosial, ekonomi, lingkungan, spiritual, dan fungsional status (Liu et.al, 2019).

\section{METODE PENELITIAN}

Desain kegiatan ini menggunakan pendekatan mix-method (kualitatifkuantitatif). Dimana tahap pertama akan melakukan pengembangan instrument pengkajian keperawatan geriatric dengan melakukan wawancara mendalam dengan perawat dan dokter spesialis penyakit dalam. Selanjutnya, setelah dilakukan uji pakar untuk instrument tersebut, maka dilanjutkan dengan uji coba (validitas dan reliabilitas) instrument pengkajian keperawatan geriatric pada 15 lansia di RSUD Banyuasin.

\section{Jenis Penelitian}

Desain kegiatan ini menggunakan pendekatan mix-method (kualitatifkuantitatif).

\section{Waktu dan Tempat Penelitian}

Lokasi yang dilakukan kegiatan ini adalah Poli Gerontik RSUD Banyuasin. Kegiatan ini dilakukan selama 2 minggu, dari tanggal 9 Desember sampai 21 Desember 2019.

\section{Target/Subjek Penelitian}

Populasi dalam penelitian ini adalah seluruh pasien lansia (> 60 tahun) yang di rawat di RSUD Banyuasin. Kemudian untuk kegiatan pengembangan instrument pengkajian keperawatan geriatric akan melakukan wawancara pada perawat dan wawancara menurut ahli/pakar yaitu dokter spesialis penyakit dalam. Dalam penelitian ini, kriteria responden yaitu 2 Perawat yang memiliki pengalaman kerja lebih dari 5 tahun di RSUD Banyuasin. 2 Dokter spesialis penyakit dalam yang ahli dibidangnya. Lansia (> 60 tahun) sebanyak 15 responden yang dirawat di RSUD Banyuasin.

\section{Prosedur}

Tahap persiapan melakukan administrative mengajukan surat dari STIKES Mitra Adiguna Palembang yang akan dilanjutkan ditembuskan ke RSUD Banyuasin. Selanjutnya dilakukan pada tahap pertama, melakukan wawancara mendalam dengan perawat dan dokter spesialis untuk mengembangkan instrument pengkajian keperawatan geriatric. Kemudian melakukan uji pakar yang dilakukan oleh dokter spesialis penyakit dalam. Kemudian menganalisa dan membuat instrument pengkajian keperawatan geriatric.

Pada tahap ke dua dilanjutkan uji coba (validitas dan reliabilitas) terhadap instrument pengkajian keprawatan geriatric pada 15 responden lansia (> 60 tahun) yang dirawat di RSUD Banyuasin. Kemudian hasil dianalisa dan ditarik kesimpulan.

\section{Data, Intrumen, dan Teknik Pengumpulan Data}

Menyiapkan pedoman wawancara, sudah membuat janji untuk wawancara dengan partisipan, selanjutnya hasil dari instrument di uji coba validitaskan. Tahap ke 1, wawancara untuk pembuatan instrument pengkajian asuhan keperawatan geriatri. Tahap ke 2 dilanjutkan uji coba instrument ke pasien lansia. 


\section{Teknik Analisis Data}

Kegiatan ini dilaksanakan di Poli Geriatri RSUD Banyuasin dengan dua tahap. Pada tahap pertama, tim melakukan wawancara mendalam kepada Kepala Ruangan Klinik Gerontik, Kasie Keperawatan, Kabid Keperawatan, Dokter penanggung jawab Poli Geriatri dan Perawat di Poli Geriatri. Tujuan dari wawancara ini untuk mendapatkan informasi terkait pengkajian khusus pasien geriatric, kemudian dikembangkan dengan beberapa teori keperawatan dan jurnaljurnal penelitian yang selanjutnya di kembangkan menjadi sebuah instrument pengkajian khusus pasien geriatric (Lansia). Setelah tim membuat instrument kemudian dilakukan uji ahli pakar dengan dokter spesialis penyakit dalam dan perawat yang sudah bekerja lama di bidang pelayanan kesehatan khususnya di bidang keperawatan gerontic.

Selanjutnya pada tahap ke 2, tim melanjutkan uji coba (validitas) instrument pengkajian asuhan keperawatan khusus geriatric kepada 15 pasien yang berkunjung ke Poli Geriatri RSUD Banyuasin.

Teknik yang digunakan adalah uji validitas konstruk (CVI), uji content validity, dan uji reliabilitas instrumen.

\section{HASIL PENELITIAN DAN PEMBAHASAN}

Pada tanggal 9-13 Desember 2020 dilakukan wawancara mendalam kepada informan dan key informan terkait dalam mengembangkan instrument pengkajian asuhan keperawatan khusus gerontic. Wawancara ini dilakukan dengan Kepala Ruangan Klinik Gerontik, Kasie Keperawatan, Kabid Keperawatan, Dokter penanggung jawab Poli Geriatri dan Perawat di Poli Geriatri. Setelah mengembangkan instrument selanjutnya dilakukan penerapan uji pakar dan selanjutnya dilakukan uji validitas dengan 15 responden pasien yang berkunjung di Poli Gerontik RSUD Banyuasin.

\section{1) Uji validitas konstruk}

Content validity index (CVI) pada pengembangan instrument pengkajian asuhan keperawatan geriatri ini digunakan untuk melihat relevansi pada tiap komponen yang dikembangkan. CVI dalam penelitian ini melibatkan dua pakar (expert) yaitu perawat dan dokter spesialis penyakit dalam. Hasil analisis CVI dengan menggunakan Aiken's V disajikan dalam tabel berikut ini.

Tabel 4.1

Hasil Validitas Uji Coba pengkajian asuhan keperawatan geriatri $(n=2)$

\begin{tabular}{|c|c|c|c|c|c|c|c|}
\hline \multirow{2}{*}{$\begin{array}{l}\text { Komponen } \\
\text { pengkajian } \\
\text { asuhan } \\
\text { keperawatan } \\
\text { geriatri }\end{array}$} & \multicolumn{2}{|c|}{ Pakar l } & \multicolumn{2}{|c|}{ Pakar 2} & \multirow[t]{2}{*}{$\Sigma S$} & \multirow[t]{2}{*}{ V } & \multirow[t]{2}{*}{ Keterangan } \\
\hline & Skor & $S$ & Skor & $\mathrm{S}$ & & & \\
\hline AKG1 & 4 & 3 & 4 & 3 & 6 & 1 & VALD \\
\hline AKG2 & 3 & 2 & 4 & 3 & 5 & 0,833 & VALD \\
\hline AKG3 & 3 & 2 & 3 & 2 & 4 & 0,667 & VALID \\
\hline AKG4 & 4 & 3 & 4 & 3 & 6 & 1 & VALD \\
\hline AKG5 & 4 & 3 & 3 & 2 & 5 & 0,833 & VALD \\
\hline AKG6 & 4 & 3 & 3 & 2 & 5 & 0,833 & VALD \\
\hline AKG7 & 4 & 3 & 4 & 3 & 6 & 1 & VALID \\
\hline AKG8 & 3 & 2 & 3 & 2 & 4 & 0,667 & VALID \\
\hline AKG9 & 3 & 2 & 4 & 3 & 5 & 0,833 & VALD \\
\hline AKG10 & 3 & 2 & 4 & 3 & 5 & 0,833 & VALD \\
\hline AKG11 & 4 & 3 & 3 & 2 & 5 & 0,833 & VALD \\
\hline
\end{tabular}

Pengujian hasil validitas konstruk menggunakan rumus Aiken's V. Rumus Aiken's V dalam menghitung CVI yang didasarkan pada hasil penilaian pakar atau panel ahli terhadap suatu item (Hendriyadi, 2014). 
Berdasarkan hasil analisis uji pakar atau CVI menggunakan rumus Aiken's V. Interpretasi hasil rumus Aiken's V yaitu koefisien berkisar 0-1 pada setiap komponen. Instrumen dikatakan valid jika nilai $\mathrm{V}$ berada antara 0 sampai 1 . Hasil analisis Aiken's V pada dua pakar yaitu 11 item pengkajian asuhan keperawatan geriatri dinyatakan valid (pada lampiran 6), dibuktikan hasil analisis berkisar antara 0,667-1.

\section{2) Uji content validity}

Uji validitas pada pengkajian asuhan keperawatan geriatri ini dilakukan dengan cara mencobakan pengkajian asuhan keperawatan geriatri ini di Poli Gerontik RSUD Banyuasin. Dengan responden sebanyak 15 orang.

Tabel 4.2 Hasil uji validitas korelasi biserial

\begin{tabular}{cccc}
\hline Item & t-hitung & t-tabel & Status \\
\hline 1 & 3,74 & 2,048 & VALID \\
\hline 2 & 4,42 & 2,048 & VALID \\
\hline 3 & 3,65 & 2,048 & VALID \\
\hline 4 & 6,46 & 2,048 & VALID \\
\hline 5 & 4,42 & 2,048 & VALID \\
\hline 6 & 4,82 & 2,048 & VALID \\
\hline 7 & 6,25 & 2,048 & VALID \\
\hline 8 & 6,18 & 2,048 & VALID \\
\hline 9 & 5,97 & 2,048 & VALID \\
\hline 10 & 4,11 & 2,048 & VALID \\
\hline 11 & 6,25 & 2,048 & VALID \\
\hline
\end{tabular}

Pengujian validitas dilakukan dengan rumus korelasi biserial. Untuk mengetahui setiap item observasi yang valid, dapat dilakukan dengan cara membandingkan antara nilai t hitung dengan $\mathrm{t}$ tabel. Dikatakan valid apabila nilai t hitung $>t$ tabel. Untuk nilai $\mathrm{t}$ hitung berdasarkan tabel $\mathrm{t}$ dengan $\mathrm{n}=30(30-2=28)$, signifikansi $5 \%=2,048$.

\section{3) Uji reliabilitas}

Pengujian reliabilitas dilakukan dengan rumus Kuder and Richardson Formula 20 (KR20). Interpretasi hasil koefisien reliabilitas menurut Sugiyono (2016), mengatakan bahwa sebuah instrumen dikatakan reliabel apabila koefisien reliabilitasnya minimal 0,3-1, semakin mendekati 1 semakin reliabel. Adapun hasil uji validitas pengkajian asuhan keperawatan geriatri disajikan dalam tabel 4.6 berikut.

Tabel 4.3

Hasil uji reliabilitas KR20

\begin{tabular}{ccccc}
\hline Item & $\mathbf{p}$ & $\begin{array}{c}\mathbf{q} \\
(=\mathbf{1}-\mathbf{p})\end{array}$ & $\mathbf{p q}$ & Status \\
\hline 1 & 0,77 & 0,23 & 0,18 & VALID \\
\hline 2 & 0,80 & 0,20 & 0,16 & VALID \\
\hline 3 & 0,87 & 0,13 & 0,12 & VALID \\
\hline 4 & 0,73 & 0,27 & 0,20 & VALID \\
\hline 5 & 0,80 & 0,20 & 0,16 & VALID \\
\hline 6 & 0,73 & 0,27 & 0,20 & VALID \\
\hline 7 & 0,87 & 0,13 & 0,12 & VALID \\
\hline 8 & 0,90 & 0,10 & 0,09 & VALID \\
\hline 9 & 0,73 & 0,27 & 0,20 & VALID \\
\hline 10 & 0,80 & 0,20 & 0,16 & VALID \\
\hline 11 & 0,87 & 0,13 & 0,12 & VALID \\
\hline Jumlah & & & 1,68 & \\
\hline
\end{tabular}

Berdasarkan hasil uji reliabilitas pengkajian asuhan keperawatan geriatri ini didapatkan hasil yaitu varian total 9,09 dengan reliabilitas sebesar 0,90 .

\section{KESIMPULAN}

Berdasarkan hasil pengembangan instrument pengkajian asuhan keperawatan khusus gerontic di RSUD Banyuasin didapatkan instrument dan penerapan instrument yang dilakukan selama 2 minggu. 
Hasil analisis Aiken's V pada dua pakar yaitu 11 item pengkajian asuhan keperawatan geriatri dinyatakan valid (pada lampiran 6), dibuktikan hasil analisis berkisar antara 0,667-1.

Hasil uji korelasi biseral, dikatakan valid apabila nilai $\mathrm{t}$ hitung $>\mathrm{t}$ tabel. Untuk nilai t hitung berdasarkan tabel t dengan $n=30(30-2=28)$, signifikansi $5 \%=$ 2,048 .

Hasil uji KR20 didapatkan Berdasarkan hasil uji reliabilitas pengkajian asuhan keperawatan geriatri ini didapatkan hasil yaitu varian total 9,09 dengan reliabilitas sebesar 0,90 .

\section{SARAN}

1. Diharapkan instrument ini dapat diaplikasikan di Poli Gerontik, rawat inap dengan pasien lansia di pelayanan kesehatan seperti rumah sakit, puskesmas dan posyandu lansia.

2. Diharapkan dapat menjadi pengembangan selanjutnya apabila ada pembaharuan-pembaharuan ilmu baru tentang keperawatan gerontik

\section{UCAPAN TERIMA KASIH}

Penulis mengucapkan terimakasih kepada :

1. Direktur RSUD Banyuasin.

2. Ns. Eka Rivana, S.Kep.,M.Kep selaku staff RSUD Banyuasin.

3. Mahasiswa S1 STIKES Mitra Adiguna Palembang.

\section{DAFTAR PUSTAKA}

Brown Wilson, C., Arendt, L., Nguyen, M., Scott, T. L., Neville, C. C., \& Pachana, N. A. (2019). Nonpharmacological Interventions for Anxiety and Dementia in Nursing Homes: A
Systematic Review. The Gerontologist cite as: Gerontologist, 2019, Vol. XX, No. XX, 1-12.

Bullock L, Bedson J, Jordan J.L, et.al. (2019). Pain assessment and pain treatment for community-dwelling people with dementia: A systematic review and narrative synthesis. Int $\mathbf{J}$ Geriatr Psychiatry. 2019;34:807-821.

Eichhorn C, Plecher D.A, Lurz M, et.al. (2019). The Innovative Reminder in Senior-Focused Technology (THIRST)-Evaluation of Serious Games and Gadgets for Alzheimer Patients. Springer Nature Switzerland AG.

Kameyama Y.U., Mori T., Isoe K.W., et.al. (2018). Development of a novel convenient Alzheimer's disease assessment scale, the ABC Dementia Scale, using item response theory. The Authors Geriatrics \& Gerontology International published by John Wiley \& Sons Australia, Ltd on behalf of Japan Geriatrics Society.

Liu S, Shen Y, dan Zheng G. (2019). Application of comprehensive nursing intervention for Alzheimer's patients and its effects on recovery of cognitive function. Int $\mathbf{J}$ Clin Exp Med 2019;12(4):4012-4019

Sofia E, Grigorios N, Marianthi A, et.al. (2019). Comparative Study and Application of the EFA-4 Diagnostic Tool to Alzheimer's Disease and Mild Cognitive Impairment. Aristotle Biomedical Journal, Vol 1, No 1 eISSN: 2653-9748

Sonja L.R dan David B. R. (2011). Geriatric Assessment Tools. Mount Sinai Journal Of Medicine 78:489-497.

Tarigan, A.P.S. (2019). Proses Keperawatan dalam Meningkatkan Kesehatan Lansia.

Williams J.P., Storlie C.B., Therneau T.M., et.al. (2018). A Bayesian Approach to Multi-State Hidden Markov Models: Application to Dementia Progression. University of North Carolina at Chapel Hill. 